\title{
Does mass spawning enhance fertilization in coral reef fish? A case study of the brown surgeonfish
}

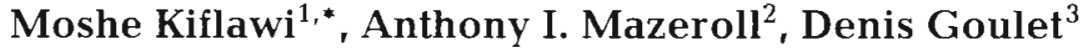 \\ ${ }^{1}$ Department of Biology, University of New Mexico, Albuquerque, New Mexico 87131, USA \\ ${ }^{2}$ Department of Life, Earth and Environmental Sciences, West Texas A\&M University, Canyon, Texas 79016, USA \\ ${ }^{3}$ Department of Biological Sciences, SUNY at Buffalo, New York 14260, USA
}

\begin{abstract}
Mass spawning' refers to the simultaneous and apparently synchronous spawning of the majority of a mating aggregation. In this study we compare the fertilization rates (FRs) attained by the brown surgeonfish Acanthurus nigrofuscus, an externally fertilizing coral reef fish, when spawning in small groups ( 4 to 15 individuals) and as part of a mass spawning aggregation (500 to 2000 individuals). Our objective is to test an hypothesized fertilization advantage to mass spawning and, thereby, to mating aggregations. Specifically, we ask whether mass spawning enhances FRs bu ond those achieved during group spawning. Results from artificial fertulization experiments demonstrated that egg viability greatly exceeds that of sperm, and suggested one means by which enhanced fertilization may be achieved. Namely, eggs not fertilized by a female's spawning partners ma! be fertilized by fresh sperm released in subsequent and nearby matings within the aggregation. Using egg samples collected in the field, we show that mass spawning makes no significant contribution to the already high FRs attained by group spawning $(\bar{x}=98.5 \%)$. We further demonstrate that FRs saturate well within the average lifespan of sperm, with over $60 \%$ of spawned eggs fertilized within $5 \mathrm{~s}$ of gamete release.
\end{abstract}

KEY WORDS: Mass spawning · Fertilization rates $\cdot$ Acanthurus nigrofuscus

\section{INTRODUCTION}

Most coral reef fish species spawn within the confines of their home range (Thresher 1984). However, several pelagic spawning species (i.e. species in which external fertilization occurs in the water column) are known to migrate for up to several kilometers and form spawning aggregations of up to several thousand individuals at specific mating sites (reviewed by Domeier \& Colin 1997). Hypothesized benefits for such localized aggregations fall into 1 of 2 categories. First, benefits may stem from the sheer presence of a large number of individuals at the spawning site. For example, large numbers may facilitate mate location and selection in species in which individuals are normally widely dispersed (Loiselle \& Barlow 1978, Colin \& Clavijo 1988), and/or swamp egg predators through simultaneous release of a vast number of gametes (Johannes 1978).

·E-mail: mkiflawi@unm.edu
Second, benefits may accrue due to the choice of specific and presumably limited spawning sites. For example, sites with favorable water-flow regimes may facilitate rapid transport of eggs away from the reef and its associated planktivorous fauna (Johannes 1978), and/or enhance dispersal and survival of larvae in a patchy and uncertain environment (Barlow 1981, Doherty et al. 1985).

Empirical evaluation of these hypotheses is, to a large extent, missing (Domeier \& Colin 1997, but see Appeldoorn et al. 1994 and Henslev ct al. 1994). Moreover, interpretation of primarily descriptive accounts often leads to equivocal conclusions (e.g. Colin \& Clavijo 1988, Shapiro et al. 1988, Domeier \& Colin 1997) This is not overly surprising as these and similar hypotheses are not mutually exclusive. Ecological differences among aggregating species can lead to differences in the selective forces responsible for the evolution and maintenance of mating aggregates. Furthermore, benefits may be garnered only under particular 
demographic or environmental conditions. Finally, migration and aggregation at specific sites and times may be a culturally transmitted tradition, adaptive at the time it was adopted by a local population but no longer so under present local conditions (Warner 1988, 1990).

Mating aggregations and synchronous spawning can enhance the fertilization success of marine invertebrates which often experience low fertilization rates (FRs) due to the relatively large distances that separate mates (Denny \& Shibata 1989, Levitan \& Petersen 1995). On the other hand, mating by pelagic spawning reef fish involves the close proximity of males and females (Thresher 1984). Consequently, mean FRs during pair spawning tend to be above $90 \%$ (Warner et al. 1995. Marconato \& Shapiro 1996, Marconato et al. 1997). These high FRs have been argued to reflect optimal gamete allocation by males, given the saturative nature of the function relating $F R$ to sperm number (Shapiro et al. 1994, Shapiro \& Giraldeau 1996). Group spawning involves a single female and several males. During group spawning, sperm competition leads to the simultaneous exposure of eggs to several ejaculates of elevated mean sizes. For example, Shapiro et al. (1994) showed that male bluehead wrasse Thalassoma bifasciatum engaged in group spawning (1 female and 5 to 20 males) released, on average, 6 times as many sperm as pair spawning males. As a result, mean FRs have been observed to reach $98 \%$ and show little variance (Marconato et al. 1997).

'Mass spawning' refers to the simultaneous and apparently synchronous spawning of the majority of a mating aggregation, and is characteristic of several aggregating species of coral reef fish (Domeier \& Colin 1997; also see 'Methods'). Presuming that very high FRs are typical of group spawning reef fish, the question remains whether mass spawning can further enhance fertilization, to any evolutionary significant extent. It is this question that we focus on. Little is known of the FRs of most pelagic spawning fish species. To date, rigorous data have been published for only 3 species (Halichoeres bivattatus, Petersen 1991; Sparisoma radians, Marconato \& Shapiro 1996; Thalassoma bifasciatum, Petersen et al. 1992, Shapiro et al. 1994, Warner et al. 1995, Marconato et al. 1997). Several factors other than sperm concentrations may contribute to fertilization success (e.g. water-flow regime; Denny \& Shibata 1989, Petersen 1991, Petersen et al. 1992), potentially resulting in FRs which are lower than perfect. Hence, at this point in time, the question of an environmentally and/or phylogenetically contingent fertilization advantage to mass spawning in reef fish seems plausible.

One means by which a fertilization advantage may be achieved is suggested by observations which show that, once released, spawned eggs remain viable considerably longer than sperm (Petersen et al. 1992, this study). Differential gamete viability is certainly not restricted to mass spawning species. However, as mass spawning may last longer than mean sperm longevity, we find it conceivable that, in species that do mass spawn, those eggs not fertilized by a female's immediate mates may be fertilized by the sperm released in subsequent and neighboring spawns within the aggregation. The ensuing increase in FR would not depend on any modification of either male or female gamete allocation strategies, and should benefit both sexes equally. It is this mechanism of fertilization enhancement that we propose to test.

\section{METHODS}

Research site and biology of Acanthurus nigrofuscus. The study was conducted from June to September 1997, along the north-western shoreline of the Gulf of Eilat (Aqaba), the Red Sea. Coral reefs along this region are fringing, often breaking into small knolls interspersed along a sandy bottom. Prevailing water currents run parallel to the reef, with a weak on-shore component driven by a predominantly southward wind (A. Genin et al. unpubl.).

Acanthurus nigrofuscus is a shallow water herbivore, common throughout the Indo-Pacific (Robertson 1983). Along the shoreline $3 \mathrm{~km}$ north of the IsraelEgypt border, A. nigrofuscus forms a distinct mating population (referred to as the 'Lighthouse population' in Myrberg et al. 1988). During the breeding season (May to September) members of this population migrate daily to form an aggregation of up to 2000 individuals at a specific spawning site (Mazeroll \& Montgomery 1995). Spawning starts around sunset, with isolated clusters of fish (1 female with 3 to 14 males) briefly breaking away from the aggregation (1 to $2 \mathrm{~m}$ upwards or sideways) to release their gametes. These isolated clusters constitute 'group spawning' Shortly thereafter, spawning activity flurries with the formation of many such clusters, either simultaneously or within seconds of one another, often extending more than a minute. We refer to this apparently synchronous spawning as 'mass spawning' (see Domeier \& Colin 1997). On occasion, mass spawning will proceed in a pulsed fashion, with 2 or 3 periods of intense activity punctuated by a period of inactivity lasting several minutes (see Robertson 1983 for similar description of mass spawning in A. nigrofuscus populations in Aldabra, Seychelles). The gamete cloud produced by mass spawns spans several. cubic meters and is often highly visible for $>2$ min after spawning has ceased (pers. obs.) 
Gamete viability (artificial fertilization). We conducted 2 artificial fertilization experiments which, together, allowed us to establish: (1) sperm viability and, thereby, the appropriate sampling latency (see below) for field collection of eggs, and (2) egg viability and, thereby, the time span over which eggs are available for fertilization during mass spawning.

Expt 1: To establish the time frame over which fertilization may occur once eggs and sperm are released into the water, we simultaneously stripped the gametes from a single male and female into separate glass beakers containing $100 \mathrm{ml}$ of fresh sea water. Immediately upon gamete extraction we used $20 \mathrm{ml}$ plastic syringes to obtain either four or five $3 \mathrm{ml}$ samples of the egg suspension. At $10 \mathrm{~s}$ after stripping, we added $3 \mathrm{ml}$ of the sperm suspension to one of the syringes. Subsequently, at $10 \mathrm{~s}$ intervals, $3 \mathrm{ml}$ of sperm were drawn into one of the remaining syringes (i.e. a total sampling time of 40 or $50 \mathrm{~s}$ ). The gamete suspension was shaken gently and left in the syringe for 1 to $1.5 \mathrm{~min}$ before being transferred into $20 \mathrm{ml}$ vials and topped with additional sea water. We repeated the experiment with 10 pairs.

Expt 2: To establish the time frame over which eggs may be fertilized by fresh sperm (i.e. egg viability), we stripped the eggs from a single female into $100 \mathrm{ml}$ of sea water and immediately divided the suspension among 5 or 6 glass beakers which contained additional sea water (total volume $100 \mathrm{ml}$ ). At $30,60,90,120,180$ and $300 \mathrm{~s}$, we stripped the sperm from a new male directly into one of the beakers and gently stirred the suspension. A $20 \mathrm{ml}$ sub-sample was transferred from each beaker into a plastic vial for later analysis. Changes in water temperature within the beaker were minimal $\left(<1^{\circ} \mathrm{C}\right.$ over $\left.5 \mathrm{~min}\right)$. We repeated the experiment with 6 females.

Fish used in these experiments were herded, while on route to the spawning site, into a monofilament barrier net ( $50 \mathrm{~m} \times 2.5 \mathrm{~m} \times 3 \mathrm{~cm}$ mesh) and captured using large hand nets. Once captured, we transferred the fish to shore where they were held in $180 \mathrm{l}$ containers. Both experiments were conducted immediately following capture and spanned 3 evenings. To establish FRs, we examined 100 of the sampled eggs under a dissecting microscope, 2 to $4 \mathrm{~h}$ after the gametes were mixed. Fertilized, developing eggs were clearly distinguished from undeveloping eggs by the presence of dividing cells.

As a caveat, we note that sperm found in exceedingly high concentrations are known to lose their viability faster than sperm found in more dilute suspensions. For example, Ginzburg (1968) reports how a 10-fold dilution of lake trout sperm $(1: 50$ to $1: 500$, by volume) more than doubled its average longevity (ca 22 s to ca 55 s, respectively). This 'dilution effect' is attributed to changes in the physical properties of the sperm suspension, e.g oxygen and carbon dioxide partial pressures (Ginzburg 1968, p. 128). We estimate our working sperm dilution at around 1:200, presumably higher than under natural conditions. While we can offer no quantitative evaluation of the consequence (to relative sperm longevity) of this dilution, we note that our findings may underestimate true longevity values.

Field collection of eggs. Spawning took place daily at a depth of approximately 10 to $12 \mathrm{~m}$, roughly 4 to $6 \mathrm{~m}$ above the bottom. Following a group spawning event, a SCUBA diver situated 4 to $5 \mathrm{~m}$ away from the aggregation approached the gamete cloud, keeping it in sight as it dissipated. After waiting a predetermined period of time (hereafter referred to as sampling latency), the diver collected an egg sample by passing a net through the water carrying the gamete cloud (total sweep times are provided below). We used a conical plankton net (100 $\mu \mathrm{m}$ mesh size), mounted on a $20 \mathrm{~cm}$ diameter aluminum frame. The net was fitted with a cod-end consisting of a $1 \mathrm{l}$ plastic container, 2 sides of which were replaced with $300 \mu \mathrm{m}$ plankton mesh. Upon collection, the diver removed and capped the cod-end, which was then placed inside a zip-lock polythene bag. Subsequently, the net was cleaned underwater and fitted with a new cod-end. At the laboratory, we gravity filtered the samples $(300 \mu \mathrm{m}$ mesh size) to remove the eggs for counting. We used a Folsom splitter to fractionate extremely concentrated samples before proceeding to count one of the resulting aliquots.

Fertilization kinetics. Gamete clouds formed during group spawns dissipate quickly, often disappearing completely after 20 to $25 \mathrm{~s}$. To examine how fertilization proceeds from the time of gamete release we obtained between 2 and 5 samples of eggs released during group spawns, at each of the following sampling latencies: 5, 10, 15, 20 and $25 \mathrm{~s}$ (total sample size: $N=20$ ). Sampling was at random with respect to latencies and covered 7 consecutive days. To avoid repeated exposure of unfertilized eggs to viable sperm (see 'Sampling methodology-evaluation'), we relied on a single sweep of the net through the gamete cloud (ca 1 s) to obtain each of the samples. On average, we analyzed 208 ( \pm 52 SD) undamaged eggs per sample.

Fertilization rates of group and mass spawns. Two group spawning samples, together with 1 subsequent sample of the gamete cloud formed during mass spawning, were obtained on each of $9 \mathrm{~d}$. We waited $30 \mathrm{~s}$ from gamete release prior to collecting the group spawning samples. To obtain a sufficient number of eggs for analysis, the net was passed repeatedly (total sweep time: 5 to $10 \mathrm{~s}$ ) through the volume of water in which the gamete cloud was last visible. Mass spawn- 
ing samples were collected $30 \mathrm{~s}$ after all spawning had ceased. On 5 separate occasions, group spawning samples were obtained 1 min from the time of gamete release. As the gamete cloud was dissipating, it was approached by the diver who released a small volume of flourescein dye to mark where the cloud was last visible. Once the minute was over, the diver proceeded to pass the net through the dye cloud and its surroundings. On 3 of these 5 occasions we also obtained a subsequent sample from the mass spawning event. Petersen et al. (1992) showed that flourescein has no ill effects on fertilization success.

We used a Wilcoxon matched pairs signed ranks test to compare FRs achieved in group and mass spawning, paired according to sampling day. Only those samples containing $>30$ undamaged eggs were considered in the analysis (mean $\pm 1 \mathrm{SD}: 126 \pm 56, \mathrm{~N}=21$ and $186 \pm$ $58, N=12$ for group and mass spawns, respectively). Estimates of group FRs were based, when possiblc, on the average of the 2 daily samples. Data were pooled across both group spawning sampling latencies $130 \mathrm{~s}$, $N=9$ and $1 \mathrm{~min}, \mathrm{~N}=3$; for statistical justification, see 'Sampling methodology - evaluation').

Flow speed and fertilization success. Water turbulence and flow speed can affect FRs (Denny \& Shibata 1989, Petersen et al, 1992). Spawning at a depth of roughly $10 \mathrm{~m}$ below the surface and $4 \mathrm{~m}$ above a sandy bottom means that spawned gametes experience little ambient turbulence. To investigate the effect of flow speed, we correlated (Spearman ranks correlation) FR estimates with ambient speeds at the time of spawning, subjectively ranked as weak, medium or strong. We conducted separate analyses for group and mass spawns ( $N=21$ and $N=12$, respectively), while pooling data across the 2 group spawning sampling latencies. Based on a limited number of actual flow speed measurements, we estimated ranks as corresponding with speeds of ca 4,10 and $16 \mathrm{~cm} \mathrm{~s}^{-1}$. Measurements were obtained (courtesy of A. Genin) using an electromagnetic current meter (Model S4, InterOcean, San Diego, USA) deployed $500 \mathrm{~m}$ north of the spawning site at depths of 15 and $0.8 \mathrm{~m}$ above the bottom.

Statistics. Relatively small sample sizes and instances of unavoidable heteroscedasticity required our use of non-parametric methods for most analyses of variance and correlation (SPSS version 6.1.2). Reported mean FRs and percent damaged eggs, as well as the accompanying $95 \%$ confidence limits (CL), are back-transformed from statistics calculated for arcsin transformed data. All reported significance levels are 2-tailed.

Sampling methodology-evaluation. The importance of sampling methodology to the correct interpretation of FR data has been recently stressed by Marconato et al. (1997). We see 2 potential pitfalls to our use of a net in the field collection of eggs. First, the net may differentially damage fertilized and unfertilized eggs, thereby biasing our estimates of fertilization success (see 'Calculating FRs-evaluation'). Second, by repeatedly passing the net through the gamete cloud, netted eggs are more likely to encounter viable sperm than under normal conditions, thereby biasing fertilization success.

Damaged eggs are white/opaque in appearance (Marconato et al. 1997). All our field samples included a percentage of damaged eggs, which were extremely rare in samples obtained from stripped females $(\bar{x}=$ $24.1 \%, \mathrm{CL}=20.8$ to $27.6 \%, \mathrm{~N}=41$ ). To examine for differential egg damage according to fertilization status, we simultaneously stripped a male and a female into $100 \mathrm{ml}$ of fresh sea water. We gently stirred the suspension and, within 2 to $3 \mathrm{~s}$, transferred $20 \mathrm{ml}$ into a plastic bag containing 500 to $600 \mathrm{ml}$ of sea water and added the remainder to $90 \mathrm{i}$ of sea water held inside a large container. Thirty seconds from stripping we used the net to re-collect the eggs from inside the container (total sweep time 5 to $10 \mathrm{~s}$ ). We repeated the procedure with 8 females. Concomitantly, we replicated the protocol using only unfertilized eggs obtained from 8 additional females. We later examined the samples for the proportion of damaged eggs, calculated as their fraction of the entire sample. In the 8 fertilized samples, we further examined undamaged eggs for FR.

The use of a net had a highly significant effect on the extent of damage sustained by sampled eggs $(\bar{x}=$ $0.05 \%, \mathrm{CL}=0$ to $0.2 \%$ and $\bar{x}=7.2 \%, \mathrm{CL}=5.6$ to $8.9 \%$ for bagged and netted samples, respectively; Wilcoxon matched pairs signed ranks test: $Z=3.5, \mathrm{~N}=16, \mathrm{p}=$ $0.0004)$. However, we found no evidence for differential egg damage. Among the netted samples, the percent of damaged eggs did not differ significantly between the fertilized and unfertilized samples $(\bar{x}=$ $8.5 \%, \mathrm{CL}=5.5$ to $11.5 \%$ and $\bar{x}=6.2 \%, \mathrm{CL}=4.8$ to $7.8 \%$, respectively; Mann-Whitney $U$-test: $U=20.0$, $\mathrm{N}=16, \mathrm{p}=0.203$ ). Furthermore, FR did not correlate significantly with the percent of damaged eggs (Spearman ranks correlation: $r_{\mathrm{S}}=-0.633, \mathrm{~N}=8, \mathrm{p}=0.092$ ). Finally, as all samples were examined 2 to $4 \mathrm{~h}$ from stripping, the low percentage of white/opaque eggs in the bagged sample suggests that the unfertilized eggs of Acanthurus nigrofuscus do not degenerate over time to take on the appearance of damaged eggs (Marconato et al. 1997).

The mean FR of bagged eggs was slightly, although significantly, higher than that of netted eggs $(\bar{x}=$ $99.8 \%, \mathrm{CL}=99.4$ to $100 \%$ and $\bar{x}=97.7 \%, \mathrm{CL}=96.6$ to $98.5 \%$, respectively; Mann Whitney $U$-test: $U=3.0$, $N=16, p=0.0016$ ). D. Y. Shapiro (pers. comm.) raised the possibility that use of the net may prevent fertilized eggs from developing to the point at which they 
may be recognized as such. While this possibility may explain the observed difference in FRs, we suspect the reason to lie elsewhere. Stripped sperm and eggs were mixed and immediately (2 to 3 s) transferred into either a bag (dilution of 1:25) or a large container (dilution of over 1:1000). We suggest that it is the artificially elevated final gamete concentrations within bags which is responsible for the observed difference in FRs. In conclusion, it would appear that if the net was differentially affecting fertilized versus unfertilized eggs, to an extent not detectable by our analysis, it would cause our measures of FR to only slightly underestimate true values (see 'Calculating FRsevaluation').

To circumvent artificial enhancement of $F R$ due to repeatedly exposing eggs to viable sperm, we collected the group spawning samples $30 \mathrm{~s}$ from the time of gamete release. By this time, mean sperm viability is reduced to $19.2 \%(C L=8.7$ to $32.7 \%$ ) of its viability at the time of release (see 'Results'). A Mann-Whitney $U$ test on FRs of group spawns collected at 30 and $60 \mathrm{~s}$ from gamete release show no significant effect of sampling latency $(\bar{x}=98.6 \%, C L=97.7$ to $99.3 \%, N=12$ and $\bar{x}=99.2 \%, C L=98.4$ to $99.7 \%, N=9$, respectively; $U=32.5, \mathrm{p}=0.122$ ). This, in itself, does not dispel the possibility of artificially enhanced FR. Yet, it demonstrates that. FR does indeed reach the levels observed at $30 \mathrm{~s}$, even when sampling is delayed beyond the lifespan of sperm. On the other hand, the kinetics which relate FR and the time elapsed from gamete release clearly demonstrates that fertilization is completed well before our sampling latency of $30 \mathrm{~s}$ (see 'Results').

Calculating FRs-evaluation. Unlike Marconato et al. (1997), we exclude damaged eggs from our calculation of FRs. We take FR to equal $F /(F+U)$, where $F$ and $U$ are the number of fertilized and unfertilized eggs per sample, respectively. Our justification is as follows: Let $F R_{D}=(F+p \times D) /(F+U+D)$ be the true measure of fertilization rates as it further considers both the number of damaged eggs per sample $(D)$, and the proportion of damaged eggs which were fertilized at the time of collection $(p)$. When $D=0, \mathrm{FR}_{D}=$ $F R$. Increasing $D$ will cause $F R$ to underestimate $F R_{D}$ if $p>F /(F+U)$ (i.e. if the net differentially damages fertilized eggs) and to overestimate it if $p<F /(F+U)$ (i.e. if the net differentially damages unfertilized eggs). However, if $p=F /(F+U)$ then $F R=F R_{D}$. By showing that fertilized and unfertilized eggs are equally damaged when netted $30 \mathrm{~s}$ from release (see 'Sampling methodology - evaluation'), we can safely argue that $p=F /(F+U)$ and that our exclusion of damaged eggs in the calculation of FR is justified. Admittedly, we cannot make a similar argument for samples collected at shorter latencies.

\section{RESULTS}

When both eggs and sperm are allowed to age simultaneously, fertilization capacity under artificial conditions drops dramatically between 20 and $30 \mathrm{~s}$ after stripping $(\bar{x}=97.3 \%, C L=94.8$ to $99.0 \%$ and $\bar{x}=$ $19.2 \%, C L=8.7$ to $32.7 \%$, respectively; Fig. 1a). When only eggs are aged, fertilization capacity drops slowly for the first $90 \mathrm{~s}$, with an average of $90.5 \%$ (CL $=86.0$ to $94.1 \%$ ) of eggs still viable $120 \mathrm{~s}$ from stripping (Fig. 1b).
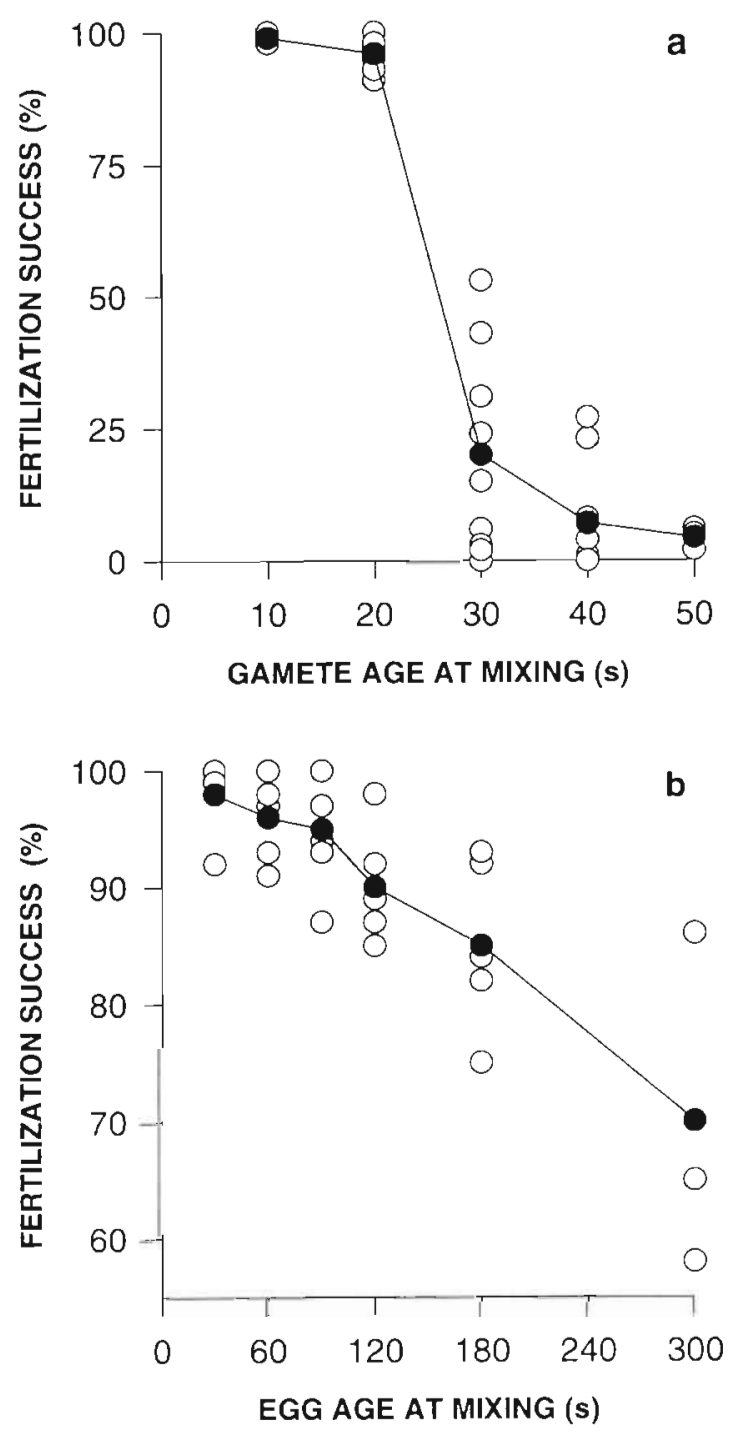

Fig. 1. Results of artificial fertilization experiments in. which: (a) both gametes have been aged separately prior to mixing (sample size per 'gametes age at mixing': $N=10$, except for 50 s: $N=3$ ); (b) only eggs have been aged and mixed with fresh sperm (sample sizes per 'egg age at mixing' $N=6$. except for $300 \mathrm{~s}: N=3$ ). Open and filled symbols represent individual data points and means, respectively. Note differences in scale along both axes 


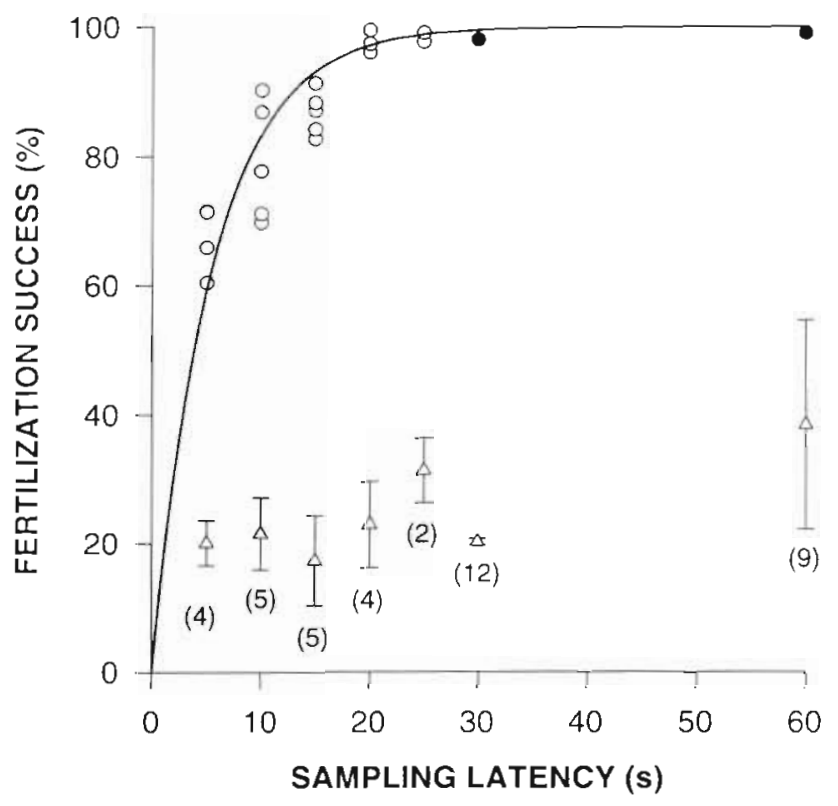

Fig. 2. Empty circles depict fertilization rates (FRs) attained in group spawns as a function of the time interval which separated gamete release and sampling. Filled circles depict mean FRs used to compare group and mass spawning. The curve is an exponential relation fitted by the Marquardt-Levenberg algorithm to data represented by open symbols $\{F R=100 \times$ $[1-\exp (-0.179 \times$ sampling latency) $]\}$. Triangles depict the mean ( $\pm 1 \mathrm{SD}$ ) proportion of damaged eggs. Sample sizes are provided in parentheses

In the field, the majority of eggs released in group spawns is fertilized within the first few seconds, with a mean FR of $67.4 \%(\mathrm{CL}=62.2$ to $72.5 \%)$ attained at $5 \mathrm{~s}$. Once $20 \mathrm{~s}$ have elapsed, FR reaches an average of $98.5 \%$ (CL $=96.5$ to $99.6 \%$ ). Overall, the kinetics relating the FRs of group spawns and the elapsed time from gamete release is well matched by an exponential function saturating at 20 to $25 \mathrm{~s}$ \{non-linear regression using the Marquardt-Levenberg algorithm and untransformed data: $F R=100 \times[1-\exp (-b \times$ latency $)]$, where $b=0.179 \pm 0.012 ; \mathrm{r}^{2}=0.649 ;$ Fig 2$\}$. We found no significant correlation between FR and the percent of damaged eggs across the early sampling latencies for $5 \leq$ latency $\leq 20 \mathrm{~s}: r_{\mathrm{s}}=0.113, \mathrm{p}=0.657, \mathrm{~N}=18$; for $5 \leq$ latency $\leq 25 \mathrm{~s}: r_{\mathrm{s}}=0.243, \mathrm{p}=0.243, \mathrm{~N}=20$ ). This lack of a significant relation confirms that the pattern shown in Fig. 2 is not an artifact generated by potentially differential affects of the net on eggs at various sampling latencies.

We found no significant difference between FRs attained during mass and group spawning $(\bar{x}=98.9 \%$, $\mathrm{CL}=98.4$ to $99.3 \%$ and $\bar{x}=98.5 \%, \mathrm{CL}=98.0$ to $99.0 \%$, respectively: Wilcoxon matched pairs signed ranks test: $Z=0.88, N=12, p=0.379$ ) Ambient flow speed had no significant effect on FRs attained in either group or mass spawning (Spearman ranks correlation: $r_{s}=0.037, p=0.87$ and $r_{s}=0.168, p=0.37$, respectively).

\section{DISCUSSION}

Species from at least 9 families of coral reef fish form large mating aggregations as part of their reproductive repertoire (Domeier \& Colin 1997). The formation of these aggregations often entails extensive migration to the mating site, presumably at some cost. Hence, it is reasonable to suspect that spawning as part of such site-specific aggregations provides, or has provided in the past, some selective advantage(s). Several mutually non-exclusive hypotheses have been advanced to explain mating aggregations in reef fish. In this study we have tested one such hypothetical advantage: the enhancement of FRs through mass spawning beyond those attainable through a spawning mode which does not necessitate extensive migration and aggregation, namely, group spawning

We must emphasize that in our study population, both group and mass spawning do involve migration to and aggregation at the same site (see also Robertson 1983 for similar accounts of Acanthurus nigrofuscus populations in Aldabra and Palau). Having observed tens of spawning events, it is our impression that no differences exist in the mean number of fish participating in the spawning rushes of mass versus group spawning, nor in their behavior during the spawning rush. Hence, we proceed by treating mass and group spawning, in this population, as differing only with respect to the co-occurrence of synchronous spawning by neighboring groups. We have no explanation as to why a small number of females (and males) that have undertaken the migration 'choose' to mate just prior to mass spawning. One possibility is that these isolated group spawning events represent an initial 'failure' in synchronizing mass spawning. In any case, the spatial and temporal overlap of these nominal spawning modes provided us with an ideal system with which to test the fertilization-advantage hypothesis. Yet, for any evolutionary inferences to be made based on this study, we must assume that if group spawning were to take place independently of extensive migration and aggregation (as is the case with other species) they would be similar in all other respects to those described here.

The slow decline in the fertilization capacity of aged eggs mixed with fresh sperm (Fig. 1b) implicates the loss of sperm viability as responsible for the rapid loss of fertilization capacity upon simultaneous gamete release (Fig. 1a). This difference in the rates by which sperm and eggs lose their viability (see also Petersen et 
al. 1992) suggests one means by which mass spawning can enhance fertilization. The loss of sperm viability stands to limit fertilization 20 to 30 s from the time of gamete release. However, eggs not fertilized by the sperm of mated males may still be fertilized by fresh sperm released in subsequent and neighboring spawns. Our comparison of FRs attained in mass versus group spawns found no significant difference, and shows that such a mechanism is not operating; at least not in our study population. An obvious reason for this lack of a difference resides in the fertilization kinetics of gametes released during group spawning. Specifically, over $60 \%$ of group spawned eggs are fertilized within the first $5 \mathrm{~s}$ (Fig. 2), with little room left for improvement beyond $20 \mathrm{~s}(\bar{x}=98.5 \%)$. Similarly high FRs have been observed in the only other group spawning species examined, Thalasoma bifasciatum (Marconato et al. 1997).

The sperm of Acanthurus nigrofuscus exhibit no substantial loss of viability during the first $20 \mathrm{~s}$ from their release (Fig. 1a). Interestingly, FRs of group spawns saturates at 20 to $25 \mathrm{~s}$ (Fig. 2). This correspondence suggests a potential causal relationship between sperm longevity and the fertilization process, but reveals little of its nature. Increasing intensities of sperm competition have been predicted to select for faster and, thereby, larger sperm at the expense of reduced sperm longevity (Ball \& Parker 1996). A recent comparative study of externally fertilizing fish (Stockley et al. 1997 ) refutes the predicted positive relationship between sperm size and sperm competition intensity, while demonstrating a trade-off between sperm size and longevity across species. To the extent that the sperm of A. nigrofuscus is typical of externally fertilizing fish, our finding that mean sperm longevity exceeds the time required to achieve essentially perfect FRs further suggests that sperm size and longevity are subject to a selective regime other than that proposed by Ball \& Parker (1996).

Group spawning appears in the reproductive repertoire of the majority of fish species that form mating aggregations (Domeier \& Colin 1997). Furthermore, near perfect FRs may well prove to be a general characteristic of group spawning. If so, we would be led to conclude that mass spawning contributes no current fertilization advantage to the mating aggregations of coral reef fish; at least not in the sense intended here. However, the question of whether any variation exists in the FRs of group spawning coral reef fish is largely unexplored.

Acknowledgements. We are indebted to A. Baranes and the staff of the Interuniversity Institute of Eilat for the use of their facilities and for making us feel at home. M.K. extends his gratitude to A. Genin and members of his laboratory for their generous hospitality, and to R. Erlich, D. Torovtzky, D. Mohar,
A. Avishal, G. Ribak, R. and C. Wyeth and L. Green for their invaluable field assistance. M.K. was funded by the Tobias Landau fellowship for manne research, and by grants provided by The Explorers Club, The Lerner-Gray Fund and the RPT, SRAC and GRAC grants administered by the University of New Mexico. D.G. and A.I.M. were funded by a grant from the Center for Field Studies. A.I.M. is supported by a West Texas A\&M University Research Grant. We are grateful to $R$. R. Warner and D. Y Shapiro, who provided comments which greatly improved an early draft of this manuscript. L. Green, T. L. Goulet, J. Feng, M. Horning, A. Pai, O. Rios-Cardenas, $M$. Webster, $H$. Chuang and 6 anonymous reviewers provided additional comments for which we are thankful.

\section{LITERATURE CITED}

Appeldoorn RS, Hensley DA, Shapiro DY (1994) Egg dispersal in a Caribbean coral reef fish, Thalassoma bifasciatum. II. Dispersal off the reef platform. Bull Mar Sci 54:271-280

Ball M, Parker GA (1996) Sperm competition games: external fertilization and 'adaptive' infertility. J Theor Biol 180: $141-150$

Barlow GW (1981) Patterns of parental investment, dispersal and size among coral-reef fishes. Environ Biol Fish 6: $65-85$

Colin PL, Clavijo IE (1988) Spawning activity of fishes producing pelagic eggs on a shelf edge coral reef, southern Puerto Rico. Bull Mar Sci 43:249-279

Denny MW, Shibata MF (1989) Consequences of surf-zone turbulence for settlement and external fertilization. Am Nat 134:859-889

Doherty PJ, Williams DM, Sale PF (1985) The adaptive significance of larval dispersal in coral reef fishes. Environ Biol Fish 12:81-90

Domeier ML, Colin PL (1997) Tropical reef fish spawning aggregations: defined and reviewed. Bull Mar Sci 60: $698-726$

Ginzburg AS (1968) Fertilization in fishes and the problem of polyspermy. Academy of Sciences of the U.S.S.R. Translated from Russian [Detlaf TA (ed)]. Israel Program of Scientific Translation, Jerusalem 1972

Hensley DA, Appeldoorn RS, Shapiro DY, Ray M, Turingan RG (1994) Egg dispersal in a Caribbean coral reef fish, Thalassoma bifasciatum. I. Dispersal over the reef platform. Bull Mar Sci 54:256-270

Johannes RE (1978) Reproductive strategies of coastal marine fishes in the tropics. Environ Biol Fish 3:741-760

Levitan DR, Petersen C (1995) Sperm limitation in the sea. Trends Ecol Evol 6:228-231

Loiselle PV, Barlow GW (1978) Do fishes lek like birds? In: Reese ES, Lighter FJ (eds) Contrasts in behavior. John Wiley and Sons, New York, p 31-76

Marconato A, Shapiro DY (1996) Sperm allocation, sperm production and fertilization rates in the bucktooth parrotfish. Anim Behav 52:971-980

Marconato A, Shapiro DY, Petersen CW, Warner RR, Yoshikawa T (1997) Methodological analysis of fertilization rate in the bluehead wrasse Thalassoma bifasclatum: pair versus group spawns. Mar Ecol Prog Ser 161:61-70

Mazeroll Al, Montgomery WL (1995) Structure and organization of local migrations in brown surgeonfish (Acanthurus nigrofuscus]. Ethology 99:89-106

Myrberg AA Jr, Montgomery WL, Fishelson L (1988) The reproductive behavior of Acanthurus nigrofuscus (Forskal) and other surgeonfish (Fam. Acanthuridae) off Eilat, Israel (Gulf of Aqaba, Red Sea). Ethology 79:31-61 
Petersen CW (1991) Variation in fertilization rate in the tropical reef fish. Halichoeres bivattatus: correlates and implications. Biol Bull 181:232-237

Petersen CW, Warner RR, Cohen S, Hess HC, Sewell AT (1992) Variation in pelagic fertilization success: implications for production estimates, mate choice, and the spatial and temporal distribution of spawning. Ecology 73: $391-401$

Robertson DR (1983) On the spawning behavior and spawning cycles of eight surgeonfishes (Acanthuridae) from the Indo-Pacific. Environ Biol Fish 9:193-223

Shapiro DY, Giraldeau LA (1996) Mating tactics in external fertilizers when sperm is limited. Behav Ecol 7:19-23

Shapiro DY, Hensley DA, Appeldoorn RS (1988) Pelagic spawning and egg transport in coral-reef tishes: a skeptical overview. Environ Biol Fish 22:3-14

Editorial responsibility: Otto Kinne (Editor), Oldendorf/Luhe, Germany
Shapiro DY, Marconato A, Yoshikawa T (1994) Sperm economy in a coral reef fish. Thalassoma bifasciatum. Ecology $75: 1334-1344$

Stockley P, Gage MJG, Parker GA, Møller AP (1997) Sperm competition in fishes: the evolution of testis size and ejaculate characteristics. A.m Nat 149:933-954

Thresher RE (1984) Reproduction in reef fishes. TFH Publications, Neptune City, NJ

Warner RR (1988) Traditionality of mating-site preferences in a coral reef fish. Science 335:719-721

Warner RR (1990) Resource assessment versus tradition in mating-site determination. Am Nat 1.35:205-217

Warner RR, Shapiro DY, Marconato A, Petersen CW (1995) Sexual conflict: males with highest mating succons convey the lowest fertilization benefits to females. Proc R Soc Lond B 262:135-139

Submitted: March 16, 1998; Accepted: May 29, 1998 Proofs received from author(s): September 21, 1998 